\title{
Bioinsecticide Effect of Pinus merkusii Tree Bark Extract on Aedes aegypti larvae
}

\author{
Setiawan', Koerniasari', Ngadino' and Sri Agus Sudjarwo² \\ 'Study Program of Environmental Health, Polytechnic of Health, Surabaya 60115, INDONESIA \\ ${ }^{2}$ Faculty of Veterinary Medicine, Airlangga University, Surabaya 60115, INDONESIA
}

\begin{abstract}
Objective: Aedes aegypti is the vector responsible for the transmission of dengue fever, and it is a cosmotropical species that proliferates in the water stagnant areas near the houses. Therefore, it is necessary to find new bioinsectiside which is expected to have larvacidal effects. The aims of this study are to evaluate extracts of Pinus merkusii tree bark for efficacy against Aedes aegypti larvae. Methods: This experiment using a completely randomized design with 8 treatment groups. Each group contained five times repetition using 20 third instar larvae of Aedes aegypti with concentrations of Pinus merkusii tree bark extract are $0,10,20,40.80,160,320$, $640 \mathrm{ppm}$. Larval mortality was observed for $24 \mathrm{~h}$ and LC50 was analyzed using Probit analysis. Results: Ethanol extract of Pinus merkusii tree bark extract showed highest larval mortality against the larvae of Aedes aegypti with LC50 $=96.3$ ppm; LC90 $=298.4$ ppm after $12 \mathrm{~h}$, and LC50 $=58.4$
\end{abstract}

ppm; LC90 $=125.7$ ppm after $24 \mathrm{~h}$. Conclusion: These findings suggest that extracts from Pinus merkusii tree bark have larvacidal effect that can be exploited in development of new bioinsecticides.

Key words: Pinus merkusii, Larvacidal, Aedes aegypti.

Correspondence :

Prof. Sri Agus Sudjarwo.,Ph.D,

Department of Pharmacology, Faculty of Veterinary Medicine, Airlangga University, Surabaya 60115, INDONESIA.

Tel:+62-31-5992785;Fax:+62-31-5993015;

E-mail: ags158@yahoo.com

DOI: 10.5530/jyp.2017.9.24

\section{INTRODUCTION}

The most common diseases associated with mosquitoes are dengue fever, chikungunya, yellow fever and the worst, dengue hemorrhagic fever where Aedes aegypti (A. aegypti) is one of the mosquito species responsible for the transmission of these vector borne diseases. It is widely distributed in the tropical and subtropical zones. ${ }^{1,2} A$. aegypti is very closely associated with the human habitat. The geographical range of A aegypti is increasing in part due to rapid urbanization and increased global movement of people and cargo. ${ }^{3}$

The technique in controlling mosquitoes depends on the larval stages (egg, larvae, pupae, and adult) on target. Mosquito control includes targeting the adult mosquito through spraying chemical insecticides or by killing the mosquito larvae before they emerge into adults via using synthetic larvicides or botanical extracts as an alternative larvicide. The indiscriminate use of synthetic insecticides is creating multifarious problems like environmental pollution, insecticide resistance, and toxic hazards to humans. ${ }^{4}$ Globally, there have been conscientious efforts to overcome these problems, and great emphasis has been placed recently on enviro-friendly and economically viable methodologies for pest control. Natural products of plant origin are preferred over synthetic insecticides due to their eco-friendly nature. Current research trends use plant extracts as alternative larvicides because they contain various phytochemicals that are specific in killing mosquito larvae without harming other organisms and the environment. ${ }^{5,6}$ Instead of using synthetic larvicides, the use of these plant-derived products in controlling mosquito larvae is inexpensive and environment-friendly. In most parts of the world, Synthetic chemical larvicides continue to be applied for controlling mosquitoes but many of these chemicals are toxic to human, animal and plant life and resistance can be problematic in regulating the control. Phytochemicals obtained from the huge diversity of plant species are important source for safe and biodegradable chemicals, which can be screened for mosquito repellent, larvicidal, and insecticidal activities; and tested for mammalian toxicity. Therefore, researchers are currently exploiting natural substances to be used as insecticides for controlling larval mosquitoes. ${ }^{7,8}$

The phytochemicals of the plants serve as huge storage of compounds that have biological action. ${ }^{9}$ Alkaloids, flavonoid, saponins, and tannins are known to possess medicinal and pesticidal properties..$^{10}$ These phytochemicals present in the Pinus merkusii extract. It has been reported that pinus plant components like phenolics, flavonoids, tannins and other constituents can be used to treat oxidative, inflammatory and microbial. ${ }^{11}$ The aim of this study was to evaluate the potential of Pinus merkusii tree bark extract against the larvae of Aedes aegypti through larvicidal bioassays.

\section{MATERIALS AND METHODS}

\section{Mosquito culture}

Aedes aegypti colonies were maintained in our insectary in large enamel basins $(45 \times 45 \times 40 \mathrm{~cm})$ and rearing conditions were $28 \pm 2^{\circ} \mathrm{C}$ temperature, $65 \pm 5 \%$ relative humidity $(\mathrm{RH})$ and photoperiod of $14: 10 \mathrm{~h}$ light and dark period. ${ }^{12}$ The egg strips were obtained from Institute of Tropical Disease Airlangga University Surabaya to start the colony. The strips were immersed in dechlorinated tap water for hatching. Larvae were fed with a diet of finely ground brewer yeast and dog biscuits (3:1). The emerged adults were fed with rabbit blood and with $10 \%$ glucose solution. Small porcelain dishes having $50 \mathrm{ml}$ of tap water lined with filter paper was kept inside the cage for oviposition. 


\section{Preparation of Ethanol Extract of Pinus merkusii}

Plant material and extract preparation Pinus merkusii were collected from Mojolerto, Indonesia. Tree bark were cleaned and chopped into pieces. They were dried under shade at ambient temperature for 5 days and the air-dried pericarps were then ground to powder for extraction. The powdered pericarp (1 kg) was macerated with ethanol $96 \%$ (5 L) for a week at $37^{\circ} \mathrm{C}$. The supernatant was then collected and filtered through Whatman No. 1 filter paper in a Buchner funnel under vacuum. The filtrate was concentrated by evaporation with a vacuum rotary evaporator at $45^{\circ} \mathrm{C}$. The extract was dried at reduced pressure, stored at $0-4^{\circ} \mathrm{C}$ and used for the experimentation.

\section{Phytochemical analysis}

The filtrate was tested for the presence of phytochemicals such as alkaloids, flavanoids, saponins, tannins and terpenoids using standard procedures. ${ }^{13}$

\section{Larvicidal bioassay of Pinus merkusii tree bark extract}

The tests were conducted at room temperature. The Pinus merkusii extracts as larvicide were tested against the third instar larvae of A. aegypti mosquitoes. ${ }^{14}$ Five replicates of Pinus merkusii tree bark extracts dilution with $0,10,20,40,80,160,320$ and $640 \mathrm{ppm}$ concentrations were prepared. Each replicate containing $200 \mathrm{ml}$ of the described Pinus merkusii tree bark extract was placed in a $500 \mathrm{ml}$ glass beaker. 20 thirdinstar larvae of $A$. aegypti were transferred into each beaker. ${ }^{14}$ After that, the number of dead larvae in each beaker was counted after $1.5 ; 3 ; 6 ; 12$ and $24 \mathrm{~h}$. Identification of the Aedes aegypti larvae were done by tapping it with a needle in the siphon or cervical area. Each treatment was conducted in five replicates. The larvae were considered dead if, at the end of $24 \mathrm{hrs}$, they showed no sign of swimming movements even after gentle touching with a glass rod, as described in the World Health Organization's technical report series. ${ }^{15}$ The effects of the Pinus merkusii extracts were monitored through carefully counting the number of dead larvae after 24 hours of treatment, and the percentage mortality was computed.

$$
\text { Percentage mortality }=\frac{\text { Number of dead larve } \square 100}{\text { Number of larvae int roduced }}
$$

\section{Lethal Concentration of Pinus merkusii tree bark extract}

The LC50 and LC 90 of the Pinus merkusii tree bark extract that showed $100 \%$ mortality was determined by a similar procedure as mentioned above. $0,10,20,40,80,160,320$ and 640 ppm concentration were tested and the observation was recorded after $1.5 ; 3 ; 6 ; 12$ and $24 \mathrm{hrs}$ of incubation.

\section{Statistical Analysis}

The statistical tools that were used in this study are the following: the Arithmetic Mean to get the average number of dead mosquito larvae, and Probit Analysis to calculate LC50 and LC90 values to determine Lethal concentrations of the plant extracts on Aedes aegypti mosquito larvae after 24 and 48 hours of treatment

\section{RESULTS}

The preliminary phytochemical analysis of Pinus merkusii tree bark extracts (Table 1) showed the presence of alkaloids, saponins, flavonoids, triterpenoids and tannins of phytochemicals. Any of these phytochemicals, either singly or in a combination with each other could be responsible for the larvacidal activity of the Pinus merkusii tree bark extract.

Different concentrations (0,10,20,40,80,160, 320 and 640 ppm) of Pinus merkusii tree bark extract solutions were bioassayed against the
Table 1: Phytochemical analysis of extracts of Pinus merkusii tree bark

\begin{tabular}{cc}
\multicolumn{2}{c}{ Pinus merkusii tree bark extract } \\
\hline Phytochemicals & Level \\
\hline Alkaloids & +++ \\
Flavanoids & +++ \\
Saponins & + \\
Tannins & ++ \\
Terpenoids & +++ \\
\hline
\end{tabular}

+: low, ++: immediate, +++ : high

third instar larvae of Aedes aegypti. The results were recorded after 1, $3,6,12$ and 24 h of treatment (Table 2). In control treatments, no larvicidal effect was observed; the larvae remained alive, and they moulted into fourth instar larvae. Whereas, when the different Pinus merkusii tree bark extract concentrations were tested, different mortality rates were recorded with respect to exposure time.

At 20 ppm Pinus merkusii tree bark extract, the larvae remained immobile after $3 \mathrm{~h}$ of treatment. When 40 ppm Pinus merkusii tree bark extract was tested, $1.8 \%$ and $37.4 \%$ larval mortality was recorded after $1 \mathrm{~h}$ and $24 \mathrm{~h}$ of treatment respectively. When $160 \mathrm{ppm}$ Pinus merkusii tree bark extract solution was tested, $5.2 \%$ and $100 \%$ mortality was recorded after $1 \mathrm{~h}$ and $24 \mathrm{~h}$ of treatment respectively. At 160,320 ppm complete mortality was recorded after $24 \mathrm{~h}$ of exposure, while at $640 \mathrm{ppm}, 100 \%$ mortality was recorded after $12 \mathrm{~h}$. The maximum result $(100 \%)$ was recorded with 160 ppm Pinus merkusii tree bark extract concentration after $24 \mathrm{~h}$ exposure (Table 2).

After 12 h, lethal concentration 50 (50\% larvicidal activity) of Pinus merkusii tree bark extract was 96.3 ppm while lethal concentration 90 (90\% larvicidal activity) was 298.4 ppm. However after $24 \mathrm{~h}$, letha concentration (50\% larvicidal activity) of Pinus merkusii tree bark extract was $58.4 \mathrm{ppm}$ while lethal concentration (90\% larvicidal activity) was $125.7 \mathrm{ppm}$ (Table 3). The exposure time is very important for larvicidal activity of the Pinus merkusii tree bark extract solution.

\section{DISCUSSION}

The medical importance of mosquitoes as vectors for the transmission of serious diseases that cause morbidity, mortality, economical loss, and social disruption such as malaria, lymphatic filariasis, and viral diseases is well documented. Aedes aegypti, the primary carrier for viruses that cause dengue and dengue hemorrhagic fever and yellow fever, are widespread over large areas of the tropics and subtropics. ${ }^{16}$ The prevention of mosquito breeding through the use of larvicides is the most effective way to fight with this mosquito importunation. Synthetic insecticides have been used as larvicide in several countries for the last 30 years. ${ }^{17}$ However, the non-selectiveness of insecticides and harmful effects on other organisms is the major hindrance with the use of these chemical insecticides. ${ }^{18}$ The need for development of effective insecticides should be taken into consideration due to the toxicity problems, together with the increased incidence of insect resistance. In this study was undertaken to access the toxicant potential of the Pinus merkusii against mosquito larvae of $A$. aegypti.

The Pinus merkusii tree bark extracts exhibited a concentration dependent activities against Aedes aegypti larvae since the percentage mortality were observed to increase with increasing concentrations of the Pinus merkusii tree bark extracts. The increase of percentage mortality of the treated Aedes aegypti larvae is supported by the presence of phytochemicals in the Pinus merkusii extracts which have insecticidal activities. The least percentage mortality was noted in the control group ( $0 \mathrm{ppm}$ concentration) which is extremely lower compared to those in the experimental 
Table 2: Effect of different concentrations of Pinus merkusii tree bark extract solution and exposure time on larvicidal bioassay of third instar larvae of Aedes aegypti

\begin{tabular}{|c|c|c|c|c|c|}
\hline \multirow{2}{*}{$\begin{array}{l}\text { Pinus Merkusii Extract } \\
\text { (ppm) }\end{array}$} & \multicolumn{5}{|c|}{ Larval Mortality Rate (\%) After } \\
\hline & $1.5 \mathrm{~h}$ & $3 \mathrm{~h}$ & $6 \mathrm{~h}$ & $12 \mathrm{~h}$ & $24 \mathrm{~h}$ \\
\hline 0 (Control) & 0 & 0 & 0 & 0 & 0 \\
\hline 10 & 0 & 0 & 0 & 0 & 0 \\
\hline 20 & 0 & $1.6 \pm 0.3$ & $2.8 \pm 0.2$ & $4.3 \pm 0.2$ & $11.8 \pm 1.6$ \\
\hline 40 & $1.8 \pm 0.2$ & $4.1 \pm 0.5$ & $7.2 \pm 0.4$ & $17.4 \pm 1.9$ & $37.4 \pm 3.9$ \\
\hline 80 & $2.6 \pm 0.2$ & $6.9 \pm 0.2$ & $17.6 \pm 2.7$ & $32.3 \pm 2.6$ & $69.6 \pm 4.8$ \\
\hline 160 & $5.2 \pm 0.4$ & $13.5 \pm 0.7$ & $29.3 \pm 3.6$ & $76.8 \pm 6.1$ & $100 \pm 0$ \\
\hline 320 & $7.4 \pm 0.3$ & $19.8 \pm 1.1$ & $37.3 \pm 4.3$ & $91.3 \pm 4.7$ & $100 \pm 0$ \\
\hline 640 & $11.3 \pm 0.5$ & $35.8 \pm 3.7$ & $48.9 \pm 5.2$ & $100 \pm 0$ & $100 \pm 0$ \\
\hline
\end{tabular}

${ }^{*}$ The values are mean \pm SEM of five replecate.

Table 3: LC50 and LC90 of extracts of Pinus merkusii tree bark

\begin{tabular}{ccc}
\hline Time & \multicolumn{2}{c}{ Pinus merkusii tree bark Extract } \\
\cline { 2 - 3 } & LC50 $(\mathrm{ppm})$ & LC90 $(\mathrm{ppm})$ \\
\hline After 12 h & 96.3 & 298.4 \\
After 24 h & 58.4 & 125.7 \\
\hline
\end{tabular}

groups. It reveals that all tested concentrations of the Pinus merkusii tree bark extracts (20,40,80,160, 320 and 640) caused mortality of Aedes aegypti larvae in comparison to those in the control group.

Result also indicates that 80 ppm concentrations of Pinus merkusii tree bark extract have the high percentage of mortality after $24 \mathrm{~h}$. The Pinus merkusii tree bark extract high larvicidal activity is supported by the presence of phytochemicals such as alkaloids, saponins, flavonoids, triterpenoids and tannins which are known to have insecticidal and pesticidal properties. The phytochemicals of the plants serve as huge storage of compounds that have biological action. This is supported by the presence of phytochemicals such as alkaloids, saponins, and tannins are known to possess medicinal and pesticidal properties. . $^{10,11,19}$

It is further noted that the percentage mortality increased with increasing concentrations of the plant extracts. Moreover, the mortality of mosquito larvae was also increased in relation to the time of exposure. The larvicidal activity of the highest concentration $(160 \mathrm{ppm})$ of the plant extracts on A. aegypti mosquito larvae within 24 hours of exposure. Moreover, the results also exhibited that there is a significant difference on the mortality of mosquito larvae between the control group and various concentration of the Pinus merkusii tree bark extracts. This result denotes that higher concentration of the Pinus merkusii extracts would lead to greater number of mortality in the mosquito larvae.

The lethal concentrations (LC50 and LC90) values of these Pinus merkusii tree bark extracts on Aedes aegypti mosquito larvae after 24 hours of exposure are $86.7 \mathrm{ppm}$ and $148.9 \mathrm{ppm}$. It shows that Pinus merkusii tree bark extract is the most effective in terms of insecticidal activity. Results show that Pinus merkusii is highly lethal to A. aegypti larvae.

\section{CONCLUSION}

This study indicates that the ethanolic tree bark extract of Pinus merkusii has larvicidal properties and its use as a larvicide against the denguevector, Aedes aegypti mosquito should be explored. The percentage mortality increased with increasing concentrations of the Pinus merkusii tree bark extracts and also increased in relation to the time of exposure. It is worthwhile to study extensively the larvicidal properties of the Pinus merkusii by isolating and identifying the active components responsible for larval mortality, and then test them in field trials in order to assess their potential as an alternative to synthetic chemical larvicides.

\section{ACKNOWLEDGEMENT}

The authors would like to acknowledge the support of The Ministry of Health Republic of Indonesia through the Health Polytecnic Surabaya Indonesia in conducting this research work.

\section{CONFLICT OF INTEREST}

All authors declare no conflict of interest.

\section{ABBREVIATIONS USED}

There are no any typical abbreviations used in manuscripts.

\section{SUMMARY}

- Pinus merkusii tree bark extracts showed the presence of alkaloids, saponins, flavonoids, triterpenoids and tannins of phytochemicals

- The lethal concentrations (LC50 and LC90) values of these Pinus merkusii tree bark extracts on Aedes aegypti mosquito larvae after 24 hours of exposure are $86.7 \mathrm{ppm}$ and $148.9 \mathrm{ppm}$

- The ethanolic tree bark extract of Pinus merkusii has larvicidal properties and its use as a larvicide against the dengue-vector, Aedes aegypti mosquito should be explored

\section{REFERENCES}

1. Hales S, Wet ND, Maindonald J, Woodward A. Potential effect of population and climate changes on global distribution of dengue fever: an empirical model. The Lancet. 2002;360:830-4.

2. Kovendan K, Murugan K. Effective of Medicinal Plants on the Mosquito Vectors from the Different Agroclimatic Regions of Tamil Nadu, India, Adv. Environ Biol. 2011;5(2):335-44.

3. Kyle JL, Harris E. Global spread and persistence of dengue. Annu Rev Microbial. 2008;62:71-92.

4. Nayak JB, Mohan B. Larvicidal activity of Rauvolfia serpentina L. fruits against Aedes aegypti Mosquito larvae. Int Res J Biological Sci. 2015;4(12):54-6.

5. Tiwary M, Naik SN, Tewary DK, Mittal PK, Yadav S. Chemical Composition and Larvicidal Activities of the Essential Oil of Zanthoxylum armatum DC (Rutaceae) Against three Mosquito Vectors. J Vector Borne Dis. 2007;44:198-204.

6. Govindarajulu B, Srimathi A, Bhuvana R, Karthikeyan J. Mosquito Larvicidal Efficacy of the Leaf Extracts of Annona reticulata Against Aedes aegypti. Int J Curr Microbiol App Sci. 2015;4(8):132-40

7. Moretti Mario DL, Sanna-Passino G, Demontis S, Bazzoni E. Essential oil formulations useful as a new tool for insect pest control. AAPS Pharm Sci Tech. 2002;3(2):13-8.

8. Cetin $\mathrm{H}$, Erler F, Yanikoglu A. Larvicidal activity of a botanical natural product, AkseBio2, against Culex pipiens. Fitoterapia. 2004;75(7-8):724-8. 
9. Daniela M, Navarro AF, Patrícia CB, Marcelo FR, Thiago H, Patrícia MG. Larvicidal Activity of Plant and Algae Extracts, Essential Oils and Isolated Chemical Constituents against Aedes aegypti. Nat Prod J. 2013;3:268-91.

10. Azmathullah N, Asrar Sheriff, Sultan Mohideen AK. Phytochemical Screening of Calotropis procera Flower Extracts and Their Bio-Control Potential on Culex sp. Mosquito Larvae and Pupae. Int J Pharmaceut Biol Arch. 2011;2(6):1718-21.

11. Sharma A, Goyal R, Sharma L. Potential biological efficacy of Pinus plant species against oxidative, inflammatory and microbial disorders. BMC Complement Altern Med. 2016;16:35-42.

12. Kamaraj C, Bagavan A, Elango G, Zahir AA, Rajakumar G, Marimuthu S. Larvicidal activity of medicinal plant extracts against Anopheles subpictus and Culex tritaeniorhynchus. Indian J Med Res. 2011;134(1):101.

13. Parasuraman S, Sankar N, Chandrasekar T, Murugesh K, Neelaveni T. Phytochemical analysis and oral hypoglycemic activity of leaf extract of leaves of Andrographis stenophylla C.B. Clarke (Acanthaceae). Int J Appl Biol Pharm Tech. 2010;1 (2):442-8.
14. Amer A, Mehlhorn H. Larvicidal effects of various essential oils against Aedes, Anopheles, and Culex larvae (Diptera, Culicidae). Parasitol Res. 2006;99:466-72.

15. World Health Organization. Instructions for determining the susceptibility or resistance of mosquito larvae to insecticides. 1981.WHONBC/81.807.

16. Beula JM, Ravikumar S, Ali MS. Mosquito larvicidal efficacy of seaweed extracts against dengue vector of Aedes aegypti. Asian Pacific J Trop Biomed. 2011;1(2):143-6.

17. Chavasse DC, Yap HH. Chemical Methods for the Control of Vectors and Pests of Public Health Importance. Geneva Switzerland. 1997:24-7.

18. DeOmena MC, deNavarro DM, DePaula JE, Luna JS, Ferreira de Lima MR, Sant'Ana AE. Larvicidal activities against Aedes aegypti of some Brazilian medicinal plants. Bioresource. Technol. 2007;98(13):2549-56.

19. Howard AFB, Zhou G, Omlin FX. Malaria mosquito control using edible fish in western Kenya: preliminary findings of a controlled study. BMC Public Health. 2007;7:199-204

Article History: Submission Date: 30-06-16; Revision Date: 30-07-16; Accepted Date: 07-08-16.

Cite this article: Setiawan, Koerniasari, Ngadino, Sudjarwo SA.Bioinsecticide Effect of Pinus merkusii Tree Bark Extract on Aedes aegypti larvae. J Young Pharm. 2017:9(1):127-30. 